\title{
Aortic ring autograft for reconstruction of the neo-pulmonary root in the arterial switch operation
}

\author{
Osman O. Al-Radi, MBBCh, MSC, FRCSC, Jeddah, Saudi Arabia
}

\footnotetext{
From the Department of Surgery, Abdullah Bakhsh Children's Heart Center, King Abdulaziz University, Jeddah, Saudi Arabia.

Disclosures: Author has nothing to disclose with regard to commercial support.

Received for publication Oct 26, 2015; revisions received Dec 4, 2015; accepted for publication Dec 24, 2015; available ahead of print Feb 6, 2016.

Address for reprints: Osman O. Al-Radi, MBBCh, MSC, FRCSC, Department of Surgery, King Abdulaziz University Hospital, P.O. Box 80215, Bldg 10, Room 1027, Jeddah 21589, Saudi Arabia (E-mail: oradi@ kau.edu.sa).

J Thorac Cardiovasc Surg 2016;151:e89-91

$0022-5223 / \$ 36.00$

Copyright (C) 2016 by The American Association for Thoracic Surgery

http://dx.doi.org/10.1016/j.jtcvs.2015.12.054
}

The arterial switch operation (ASO) has emerged as the gold standard for repair of simple transposition of the great arteries (TGA) ${ }^{1}$ and is the operation of choice for many forms of complex TGA. ${ }^{2}$ Moreover, the medially based, trap-door-type coronary anastomosis into the neo-aortic root (NAR), as well as reconstruction of the neopulmonary root (NPR) with fresh autologous pericardium, are the prevailing variations of the ASO. Some modifications of the standard techniques are practiced to mitigate specific problems. A lengthy ascending aorta may be shortened to avoid kinking of the coronary arteries anastomosed into the NAR (G.S. Van Arsdell, MD, personal communication, The Hospital for Sick Children, Toronto, Canada,

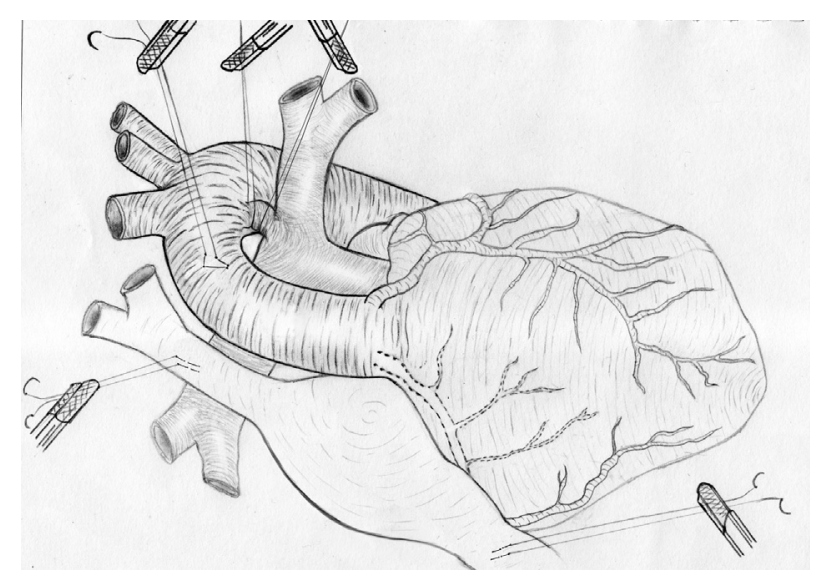

FIGURE 1. Cannulation of the ascending aorta is done as distally as possible, and the patent ductus arteriosus is ligated and divided. to repair the NPR.

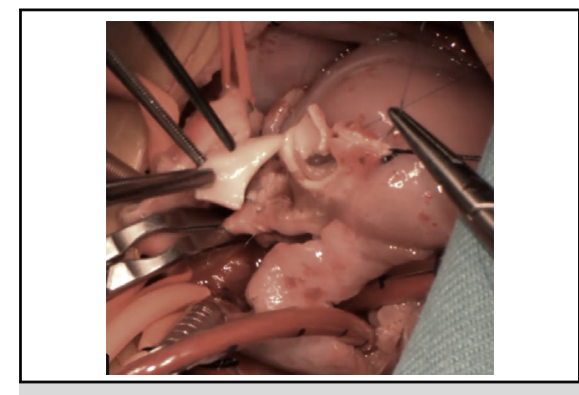

The cut aortic ring autograft is used to reconstruct the sinuses of the neo-pulmonary root.

\section{Central Message}

An autograft of the aorta to repair the pulmonary root in the arterial switch operation improves coronary position and decreases stretching of the pulmonary arteries.

See Editorial Commentary page e93.

2008). Shortening the aorta additionally places the aorta in a more-posterior position, which allows for less stretching of the branch pulmonary arteries that straddle the aorta after the LeCompte maneuver, a fairly standard part of the ASO. A round, punched-out site, instead of the trap-doortype site for coronary anastomoses, has been reported as well, with excellent results. ${ }^{3}$ The simple modification of the ASO proposed here carries all these potential advantages in addition to providing autologous vascular tissue

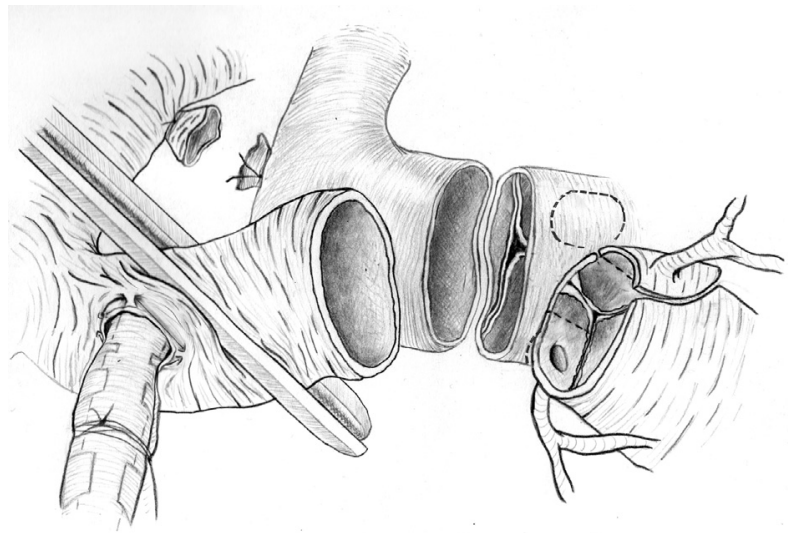

FIGURE 2. The aorta is transected $2 \mathrm{~mm}$ above the sinotubular junction. The pulmonary artery is transected below the branching point. 


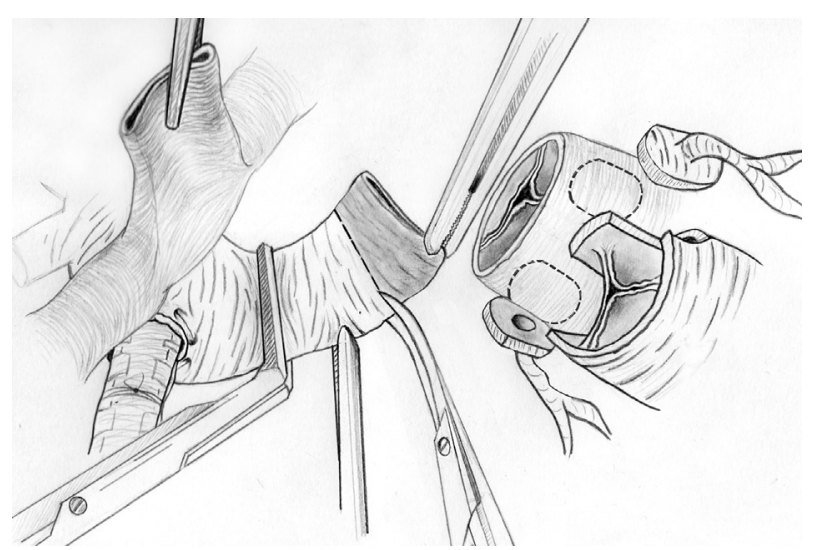

FIGURE 3. The coronary arteries are separated from the aortic root as pear-shaped or round pedicles. The LeCompte maneuver is completed, and the aortic clamp is repositioned as high as possible. A ring of aorta is harvested and placed in cold saline.

\section{METHODS}

\section{Surgical Technique}

After high aortic and bicaval cannulation (Figure 1), and establishment of cardiopulmonary bypass with moderate hypothermia, the aorta is clamped, and a single shot of cold blood cardioplegia is delivered in the aortic root. A left atrial vent is placed through the atrial septal defect. The aorta is transected approximately $2 \mathrm{~mm}$ above the sinotubular junction (Figure 2). The coronary arteries are separated from the aortic sinuses as pear-shaped or round pedicles, midway between the coronary orifice and the basal attachment of the aortic valve cusps. The adventitia around the pulmonary arteries is dissected and mobilized well into the lobar branches. The main pulmonary artery is transected approximately $2 \mathrm{~mm}$ inferior to the inferior border of the right and left pulmonary branching point. A LeCompte maneuver is performed, and the aortic crossclamp is repositioned, placing the branching pulmonary arteries superior to and underneath the clamp.

A ring of full-thickness aortic wall is harvested for later use to reconstruct the NPR (Figure 3; Video 1). The height of the ring is judged based on the desired cephalad movement of the NAR, to facilitate coronary anastomoses as low as possible without coronary kinking. This consideration usually places the coronary anastomoses in the sinuses of the NAR, or just above, with minimal disruption of the sinotubular junction.

The posterior half of the aortic anastomosis is performed with 7-0 polypropylene suturing. Positioning of the coronary artery anastomoses is facilitated by holding the NPR in a cephalad and anterior position, to

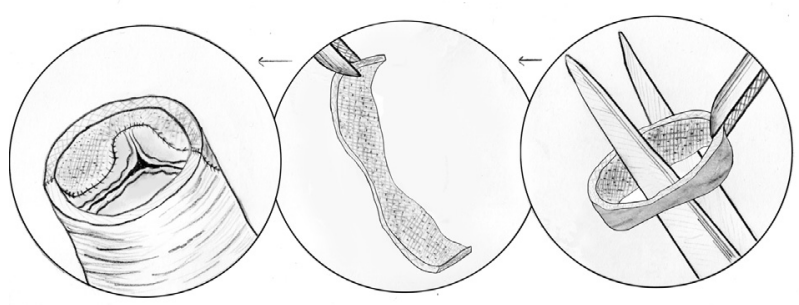

FIGURE 4. The aortic ring autograft is cut at its widest point (right), creating a bowtie-shaped autograft (middle), which is used as a single patch to reconstruct the posterior sinuses of the neo-pulmonary root (left). Alternatively, the autograft is further divided into 2 patches, to repair each sinus separately.

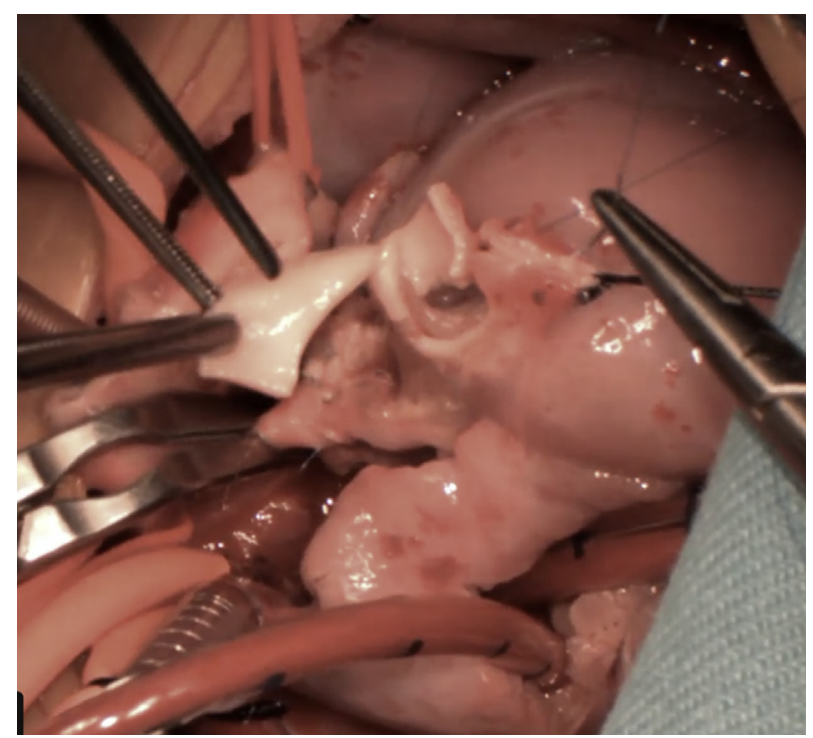

FIGURE 5. Photograph of the bowtie-shaped ring aortic autograft used to reconstruct the posterior sinuses of the neo-pulmonary root.

mimic the natural position at the time of choosing the sites for coronaries in the NAR. The coronary anastomoses are performed into 2-mm punch holes or U-shaped defects created in the NAR in the appropriate sites for the left and right coronary arteries, avoiding kinking. An 8-0 polypropylene suture is desirable for these anastomoses, to minimize bleeding. The aortic anastomosis is completed. The atrial septal defect is closed, and the vent suction is placed in the right ventricle via the tricuspid valve. The aortic clamp is removed after de-airing of the NAR.

The ring of the aortic auto graft is divided at its widest point (Figure 4). This process creates a bowtie-shaped aortic wall autograft that is used to reconstruct the NPR; a 7-0 polypropylene suture is desirable. If the coronary arteries had been harvested as pear-shaped pedicles, and the NPR root loses its circular structure, the graft is used to reconstruct the posterior 2 sinuses of the NPR, with a single patch placing the posterior commissure

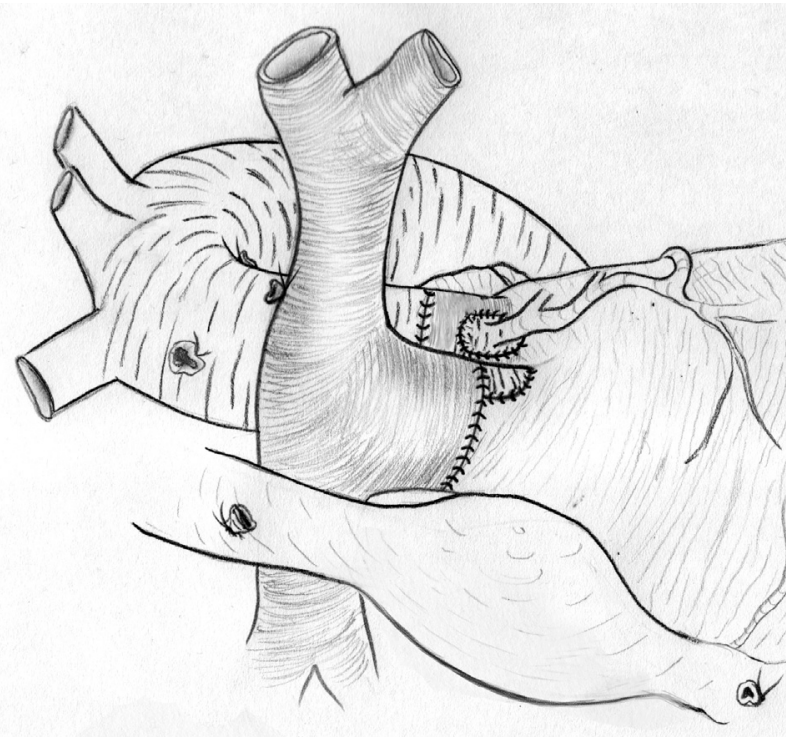

FIGURE 6. The completed repair showing the near anatomical placement of the coronary arteries and the shorter, more-posterior aorta, with minimal stretching of the pulmonary arteries. 
TABLE 1. Patient demographics and operative times

\begin{tabular}{lcc}
\hline \multicolumn{1}{c}{ Variable } & Value & Range \\
\hline Age at operation $(\mathrm{d})$ & 22 & $2-2563$ \\
Weight $(\mathrm{kg})$ & 3.45 & $2.2-15.7$ \\
Body surface area $\left(\mathrm{m}^{2}\right)$ & 0.21 & $0.16-0.66$ \\
Bypass time (min) & 93 & $67-216$ \\
Crossclamp time (min) & 55 & $40-113$ \\
Circulatory arrest time (min) & 3 & $12,19,21$ \\
Length of hospital stay (d) & 12 & $6-79$ \\
\hline
\end{tabular}

\begin{tabular}{lcc}
\multicolumn{1}{c}{ Primary diagnosis } & n & $\%$ \\
\hline Simple d-TGA & 13 & 41 \\
d-TGA with single VSD & 11 & 34 \\
d-TGA with multiple VSDs & 6 & 19 \\
DORV with transposed great arteries & 2 & 6 \\
\hline
\end{tabular}

Values are medians, unless otherwise indicated. Circulatory arrest time is given as a frequency and absolute values, respectively. $d$-TGA, Dextro-transposition of the great arteries; VSD, ventricular septal defect; $D O R V$, double-outlet right ventricle.

at the narrowest point of the bowtie-shared graft (Figure 5), or with a separate patch for each sinus. On the other hand, if the coronary arteries had been harvested as round pedicles, the graft is further divided at the narrowest point of the bowtie to create 2 grafts that can each be used to close the round defects in the NPR, leaving the pulmonary valve architecture untouched. The NAR is inspected for bleeding, because it is easier to address that issue before beginning the subsequent steps.

The reconstructed NPR is then anastomosed to the branching stump of the distal main pulmonary artery. Care must be exercised to ensure that purse-stringing of the low-pressure pulmonary arterial anastomosis does not occur. This process may be facilitated by performing the anterior half of this anastomosis with interrupted or locked, running stiches, and incising the inferior aspect of the branching pulmonary artery stump to better match the size of the reconstructed NPR (Figure 6). The right atrium is closed, with a running 6-0 polypropylene suture. Cardiopulmonary bypass is weaned off. If hemostasis is adequate, protamine is given and the procedure is completed.

\section{RESULTS}

Between January 10, 2013 and October 18, 2015, a total of 32 patients underwent the ASO; $20(63 \%)$ were male. The most common diagnosis was isolated dextrotransposition of the great arteries, in $13(41 \%)$. The patient characteristics and operative times are described in Table 1. No operative or late deaths occurred. One patient required postoperative catheterization to investigate branch pulmonary artery stenosis; however, no intervention was done, as the gradient was found to be $20 \mathrm{~mm} \mathrm{Hg}$, and echocardiographic follow-up was instituted.

\section{DISCUSSION}

A simple modification of the ASO, consisting of using a ring of aortic wall autograft to reconstruct the NPR, may achieve several desirable effects. These include improved coronary position, more-posterior placement of the aorta, which results in less stretching of the branch pulmonary arteries, and potentially better aortic and pulmonary valve function.

Illustrations were created by Belal Kamel, MD, and Medicalartists.com.

\section{References}

1. Jatene AD, Fontes VF, Paulista PP, Souza LC, Neger F, Galantier M, et al Anatomic correction of transposition of the great vessels. J Thorac Cardiovasc Surg. 1976;72:364-70.

2. Masuda M, Kado H, Shiokawa Y, Fukae K, Kanegae Y, Kawachi Y, et al. Clinical results of arterial switch operation for double-outlet right ventricle with subpulmonary VSD. Eur J Cardiothorac Surg. 1999;15:283-8.

3. Chang YH, Sung SC, Lee HD, Kim S, Woo JS, Lee YS. Coronary reimplantation after neoaortic reconstruction can yield better result in arterial switch operation: comparison with open trap door technique. Ann Thorac Surg. 2005;80:1634-40. 